\title{
Sgk: an old enzyme revisited
}

\author{
Nicolette Farman, Sheerazed Boulkroun, and Nathalie Courtois-Coutry \\ Institut National de la Santé et de la Recherche Médicale U478, Institut Fédératif de Recherche 02, \\ Université Paris 7, Faculté de Médecine Xaviér Bichat, Paris, France \\ J. Clin. Invest. 110:1233-1234 (2002). doi:10.1172/JCI200217064.
}

The elucidation of a key role for the serum- and glucocorticoid-regulated kinase (Sgk) in the regulation of the epithelial $\mathrm{Na}^{+}$channel $(\mathrm{ENaC})$ has led to substantial advances in the understanding of the signaling pathways involved in corticosteroid hormone action $(1,2)$. Indeed it is well established that the mineralocorticoid hormone aldosterone is a major regulator of body fluid homeostasis and blood pressure levels, mainly because of its capacity to modulate renal sodium reabsorption. However many aspects of this regulation pathway are not fully understood. Aldosterone binds to the mineralocorticoid receptor (MR), a member of the nuclear receptor superfamily which controls a network of genes in tight epithelia, ultimately leading to regulation of sodium entry into epithelial cells via the amiloride-sensitive $\mathrm{ENaC}$ (3). Most of the early steps of aldosterone action following MR-mediated transcriptional events are still incompletely elucidated. Differential hybridization studies have identified the serine/threonine kinase Sgk as a major transcriptional target of aldosterone. At least two other isoforms of Sgk, Sgk2 and Sgk3, have been identified after the initial characterization of Sgk (1), now referred to as Sgk1 (4). In this issue of the JCI, Wulff and col-

Address correspondence to: Nicolette

Farman, INSERM U478, Faculté de Médecine Xaviér Bichat, 16 rue Henri Huchard, BP 416, 75870 Paris Cedex 18, France.

Phone: 33-1-44-85-63-23;

Fax: 33-1-42-29-16-44;

E-mail: farman@bichat.inserm.fr.

Conflict of interest: No conflict of interest has been declared.

Nonstandard abbreviations used: serumand glucocorticoid-regulated kinase (Sgk); epithelial $\mathrm{Na}^{+}$channel (ENaC); mineralocorticoid receptor (MR); pseudohypoaldosteronism (PHA). leagues (5) generated sgk1-deficient mice and examined the effects of dietary salt-restriction on renal water and electrolyte excretion.

\section{Sgk 1 is a positive regulator of sodium transport}

Within one hour of aldosterone exposure, Sgk 1 is transcriptionally induced in both the amphibian A6 cell line and mammalian tight epithelia, and strongly stimulates sodium transport when co-expressed with the three $\mathrm{ENaC}$ subunits $-\alpha \mathrm{ENaC}, \beta \mathrm{ENaC}$, and $\gamma \mathrm{ENaC}$, in the Xenopus oocyte expression system (6-10). It has also been shown that Sgk1 promotes an increase in the number of active $\mathrm{ENaCs}$ at the surface of the oocyte (10-12). It was initially thought that Sgk1 could phosphorylate the sodium channel itself, but several attempts failed to confirm this hypothesis (13). In fact, control of the number of active $\mathrm{ENaCs}$ (including the regulation of their surface expression) appears to depend on $\mathrm{ENaC}$ interaction with the ubiquitin ligase $\mathrm{Nedd} 4$ (13). Multiple experimental approaches have led to the notion that the

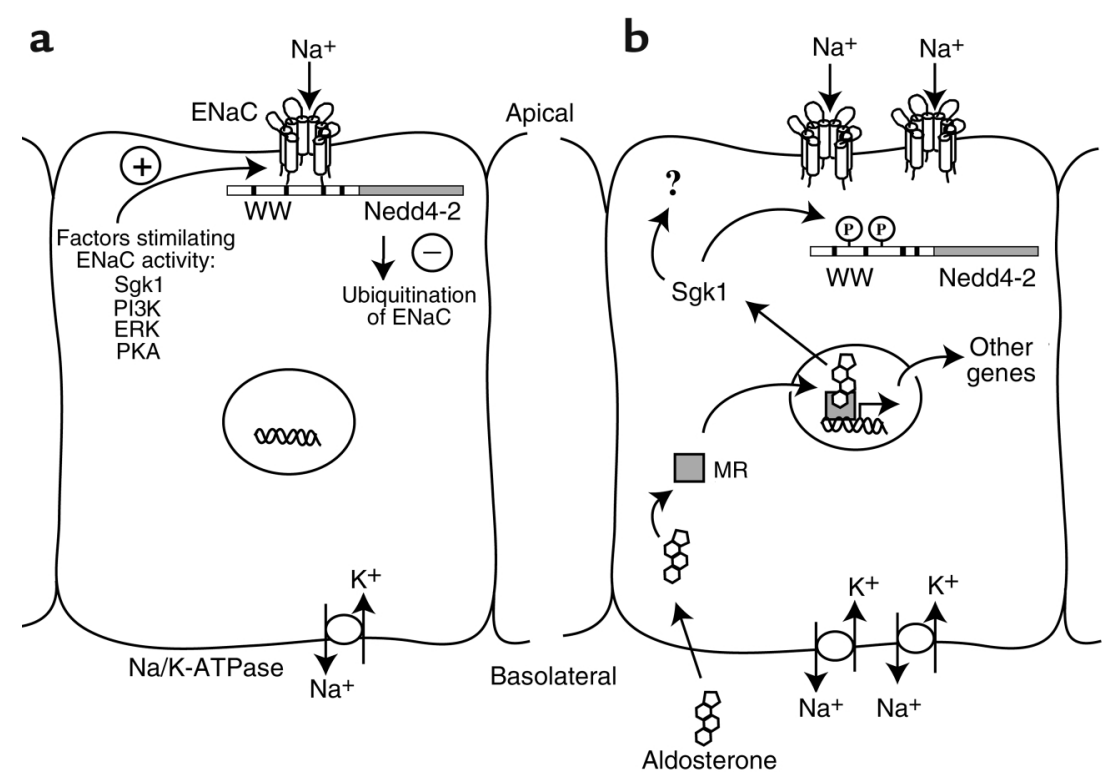

Figure 1

Mechanism of ENaC expression in an aldosterone-sensitive epithelial cell. (a) In a resting state, few $\mathrm{ENaCs}$, which facilitate sodium reabsorption in a rate-limiting fashion, are resident in the apical membrane. Factors known to enhance $\mathrm{ENaC}$ surface expression and activity are counterbalanced by retrieval of these channels from the membrane through the ubiquitination pathway mediated by Nedd4-2. (b) Shortly after aldosterone exposure and binding to the MR, transcriptional stimulation of Sgk1 leads to phosphorylation of Nedd4-2, which subsequently disrupts $\mathrm{ENaC} / \mathrm{Nedd} 4-2$ interactions. In this situation, ubiquitination of $\mathrm{ENaCs}$ is reduced, thus favoring $\mathrm{ENaC}$ residence in the apical membrane and enhanced sodium reabsorption. Afterward, stimulation by aldosterone requires successive activation of several genes resulting in sustained sodium reabsorption across the epithelium. PI3K, phosphatidylinositol-3'-kinase; ERK, extracellular signal-regulated kinase; PKA, protein kinase $\mathrm{A} ; \mathrm{Na} / \mathrm{K}-\mathrm{ATP}$ ase, sodium/potassium ATPase. 
interaction of the WW domains of Nedd4 with PY motifs in the C-terminal intracellular tail of the three $\mathrm{ENaC}$ subunits is critical for retrieval of these channels from the epithelial cell membrane, thus reducing the capacity of these cells to reabsorb sodium. Interestingly, it has recently been demonstrated that channel retrieval from the cell membrane is prevented by the phosphorylation of Nedd4-2, an isoform of Nedd4, by Sgk1 $(13,14)$. Besides direct evidence that Sgk1 indeed phosphorylates Nedd4-2, it was also shown that this event impairs Nedd4-2 interaction with the ENaC, leading to an increase in $\mathrm{ENaC}$ surface expression and activity (13-15). Thus Sgk1 and Nedd4-2 exert opposite effects on the ENaC: Sgk1 stimulates $\mathrm{ENaC}$ membrane expression and activity in response to aldosterone, while Nedd4-2 reduces it (Figure 1).

\section{Genetic disruption \\ of sgk1 generates \\ a mild salt-wasting syndrome}

Contrary to expectations, the report by Wulff et al. (5) revealed that there was no major abnormality in blood pressure and fluid handling in $s g k 1^{-/-}$mice. However, when $s g k 1^{-/}$mice were placed on a low-salt diet, their ability to retain sodium was greatly impaired. The onset of compensatory mechanisms limited the extent of urinary sodium losses, but was not potent enough to maintain body fluid homeostasis. After two days of salt restriction sgk $1^{-1-}$ mice exhibited rapid weight loss, decreased blood pressure and a decreased rate of glomerular filtration. As expected, this diet resulted in the stimulation of aldosterone secretion, which was greatly enhanced in mutant mice, due to renal sodium losses.

As it had been previously shown that Sgk1 was required for $\mathrm{ENaC}$ expression in the membrane of sodium reabsorbing epithelia, it was expected that sgk1 deletion would result in impaired $\mathrm{ENaC}$ apical localization in the tight epithelia of mice when challenged with a low salt diet and high plasma aldosterone concentration. Wulff and colleagues (5) extended their in vivo analysis of $\mathrm{ENaC}$ activity and examined the cellular localization of ENaCs at the protein level, and at the functional level, by electrophysiological analysis of the renal collecting duct.
They showed that the amiloride-sensitive transepithelial potential difference, measured in an isolated perfused tubule setting, appeared to be reduced in Sgk1 mutant mice, indicative of impaired sodium transport in the absence of Sgk1. However immunofluorescence revealed that $\mathrm{ENaCs}$ were still present within the apical membrane, strongly suggesting that factors other than Sgk1 are involved in $\mathrm{ENaC}$ maintenance at this site.

In conclusion, the authors have unmasked a salt-wasting syndrome by imposing a forced situation - a sodium-free diet - upon $s g k 1^{-/-}$mice. These results justify consideration of sgk1 as a potential causal gene in some forms of pseudohypoaldosteronism (PHA). Indeed, mutations in $\mathrm{ENaC}$ subunits (16) or the MR (17) have been evidenced in some cases of PHA, but no common genetic defect has been determined. Along the same line, recent evidence (18) supports a critical role for WNK (with no lysine) kinases in the regulation of sodium transport in the distal nephron, as highlighted by WNK kinase mutations in a rare form of hypertension, pseudohypoaldosteronism type II, also known as Gordon Syndrome.

\section{Phenotypic compensation raises new questions}

The relatively mild phenotype of this mouse model suggests that perhaps other kinases compensate for Sgk1 absence and regulate $\mathrm{ENaC}$ targeting and activity. Hyperaldosteronism due to a low-salt diet may induce other forms of Sgk (Sgk2 or Sgk3), or other related kinases such as protein kinase $\mathrm{B} / \mathrm{Akt}$, also activated by the phosphatidylinositol-3'-kinase pathway similar to Sgk1. However it is not currently known if these kinases are present in the renal collecting duct. The sgk $1^{-/-}$mouse model offers new opportunities to identify novel pathways that regulate $\mathrm{ENaC}$ activity, and reevaluate the mechanisms that control $\mathrm{ENaC}$ density at the cell surface.

Interestingly, Sgk1 has been shown to lie in the insulin signaling pathway $(2,19)$. Therefore, the observation that mice lacking Sgk1 develop a salt-wasting syndrome raises the possibility that the increased sodium retention seen in insulin resistant states could be due to inordinate Sgk1 activity. These data provide support for the notion that hypertension and insulin resistance are mechanistically linked.

1. Webster, M.K., Goya, L., Ge, Y., Maiyar, A.C., and Firestone, G.L. 1993. Characterization of sgk, a novel member of the serine/threonine protein kinase gene family which is transcriptionally induced by glucocorticoids and serum. Mol. Cell Biol. 13:2031-2040.

2. Pearce, D. 2001. The role of SGK1 in hormoneregulated sodium transport. Trends Endocrinol. Metab. 12:341-347.

3. Stockand, J.D. 2002. New ideas about aldosterone signaling in epithelia. Am. J. Physiol. 282:F559-F576

4. Kobayashi, T., Deak, M., Morrice, N., and Cohen, P. 1999. Characterization of the structure and regulation of two novel isoforms of serum- and glucocorticoid-induced protein kinase. Biochem. J. 344:189-197.

5. Wulff, P., et al. 2002. Impaired renal $\mathrm{Na}^{+}$retention in the sgk1-knockout mouse. J. Clin. Invest. 110:1263-1268. doi:10.1172/JCI200215696.

6. Chen, S.Y., et al. 1999. Epithelial sodium channel regulated by aldosterone-induced protein sgk. Proc. Natl. Acad. Sci. USA. 96:2514-2519.

7. Naray-Fejes-Toth, A., Canessa, C., Cleaveland, E.S., Aldrich, G., and Fejes-Toth, G. 1999. sgk is an aldosterone-induced kinase in the renal collecting duct. Effects on epithelial $\mathrm{Na}^{+}$channels J. Biol. Chem. 274:16973-16978.

8. Shigaev, A., Asher, C., Latter, H., Garty, H., and Reuveny, E. 2000. Regulation of sgk by aldosterone and its effects on the epithelial $\mathrm{Na}(+)$ channel. Am. J. Physiol. 278:F613-F619.

9. Brennan, F.E., and Fuller, P.J. 2000. Rapid upregulation of serum and glucocorticoid-regulated kinase (sgk) gene expression by corticosteroids in vivo. Mol. Cell Endocrinol. 166:129-136.

10. Bhargava, A., et al. 2001. The serum- and glucocorticoid-induced kinase is a physiologica mediator of aldosterone action. Endocrinology. 142:1587-1594.

11. Loffing, J., et al. 2001. Aldosterone induces rapid apical translocation of $\mathrm{ENaC}$ in early portion of renal collecting system: possible role of SGK. Am. J. Physiol. 280:F675-F682.

12. Alvarez de la Rosa, D., Zhang, P., Naray-FejesToth, A., Fejes-Toth, G., and Canessa, C.M. 1999 The serum and glucocorticoid kinase sgk increases the abundance of epithelial sodium channels in the plasma membrane of Xenopus oocytes. J. Biol. Chem. 274:37834-37839.

13. Kamynina, E., and Staub, O. 2002. Concerted action of ENaC, Nedd4-2, and Sgk1 in transepithelial $\mathrm{Na}(+)$ transport. Am. J. Physiol. 283:F377-F387.

14. Snyder, P.M., Olson, D.R., and Thomas, B.C 2002. Serum and glucocorticoid-regulated kinase modulates Nedd4-2-mediated inhibition of the epithelial $\mathrm{Na}^{+}$channel. J. Biol. Chem. 277:5-8.

15. Debonneville, C., et al. 2001. Phosphorylation of Nedd4-2 by Sgk1 regulates epithelial $\mathrm{Na}(+)$ channel cell surface expression. EMBO J. 20:7052-7059

16. Lifton, R.P. 1996. Molecular genetics of human blood pressure variation. Science. 272:676-680.

17. Geller, D.S., et al. 1998. Mutations in the mineralocorticoid receptor gene cause autosomal dominant pseudohypoaldosteronism type I. Nat. Genet. 19:279-281.

18. Wilson, F.H., et al. 2001. Human hypertension caused by mutations in WNK kinases. Science. 293:1107-1112.

19. Wang, J., et al. 2001. SGK integrates insulin and mineralocorticoid regulation of epithelial sodium transport. Am. J. Physiol. 280:F303-F313. 